\title{
Photo-leucine incorporation reveals the target of a cyclodepsipeptide inhibitor of cotranslational translocation
}

\author{
Andrew L. MacKinnon, Jennifer L. Garrison, Ramanujan S. Hegde, and Jack Taunton ${ }^{*}$ \\ Department of Cellular and Molecular Pharmacology, University of California, San Francisco, CA \\ 94158
}

\section{Abstract}

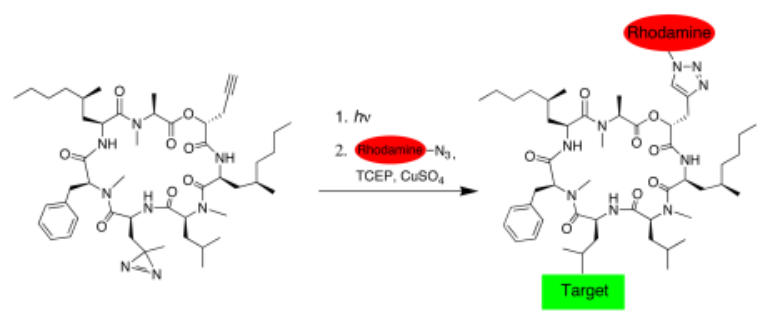

Photoaffinity labeling is a powerful tool to identify protein targets of biologically active small molecules, yet is often limited by the size, chemical properties, and availability of photo-reactive groups. We report an improved synthesis of photo-leucine, a diazirine-based photo-reactive analog of leucine, and demonstrate its incorporation into a cyclodepsipeptide inhibitor of cotranslational translocation. Photoaffinity labeling in a crude membrane fraction, followed by "click chemistry" with a rhodamine-azide reporter, enabled the identification of Sec61 $\alpha$, the structural core of the Sec61 translocation channel, as the inhibitor's target.

Photoaffinity labeling is a powerful tool to identify protein targets of biologically active small molecules and probe the structure of ligand binding sites, especially in the case of integral membrane proteins. ${ }^{1}$ A difficulty with photoaffinity labeling is that the small molecule must retain biological activity after derivatization with a photo-reactive group such as benzophenone ${ }^{2}$ or 3 -trifluoromethyl-3-phenyl diazirine. ${ }^{3}$ While these substituents are effective photo-crosslinkers and have been incorporated into small molecules, ${ }^{4}$ peptides, ${ }^{5}$ and proteins, ${ }^{6}$ their large size can potentially interfere with small molecule/protein interactions. The amino acid isosteres, "photo-leucine" and "photo-methionine", have smaller alkyl diazirine side chains and were recently used to probe protein-protein interactions after random biosynthetic incorporation in cells ${ }^{7}$ or via site-specific native protein ligation. ${ }^{8}$ By contrast, the potential for incorporating these novel photo-reactive amino acids into natural product scaffolds has not been explored. In this communication we report: (1) an improved synthesis of photo-leucine, (2) incorporation of photo-leucine and an alkyne "click chemistry" tag into a cyclodepsipeptide inhibitor of protein secretion, and (3) identification of the inhibitor's target by photoaffinity labeling. 

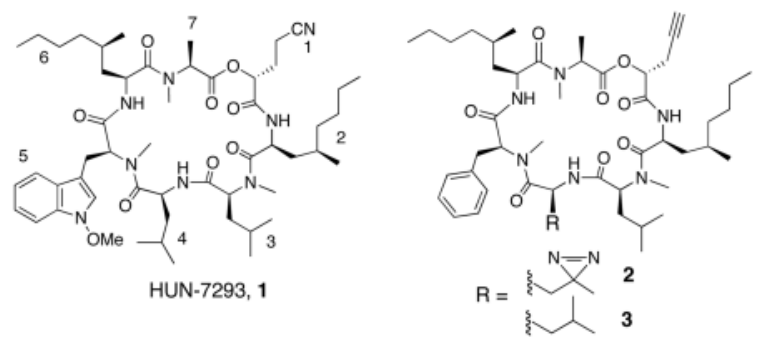

HUN-7293 (1) is a fungal cyclodepsipeptide that was first identified as an inhibitor of vascular cell adhesion molecule (VCAM) expression. ${ }^{9}$ Recently, we ${ }^{10}$ and others ${ }^{11}$ discovered that related cyclodepsipeptides potently block the cotranslational translocation of VCAM and a subset of other proteins into the endoplasmic reticulum (ER), an early step in the biogenesis of secretory and membrane proteins. Biochemical experiments revealed that these compounds act at the ER membrane to perturb interactions between nascent ribosome-associated VCAM chains and the translocation channel. A heterotrimeric membrane protein, the Sec61 complex, forms the structural core of this channel ${ }^{12}$ and thus emerged as a potential direct target of $\mathbf{1}$.

To identify the target, we designed photoaffinity probe $\mathbf{2}$, in which photo-leucine replaces leucine at position 4 of $\mathbf{1}$. We substituted $N$-methyl-phenylalanine at position 5, previously shown to have a negligible effect on potency. ${ }^{13}$ A propargyl substituent was installed at position 1 to enable $\mathrm{Cu}(\mathrm{I})$-catalyzed conjugation of a rhodamine-azide reporter ${ }^{14}$ (click chemistry) after photo-crosslinking under native conditions (Figure 1). These conservative modifications were aimed at preserving the biological potency of $\mathbf{1}$ while providing the necessary functionality for target identification.

Synthesis of $\mathbf{2}$ required Boc-(S)-photo-leucine (6), which we prepared via ozonolysis of commercially available $4{ }^{15}$ followed by formation of the diazirine by the method of Church and Weiss (Scheme 1). ${ }^{16}$ Boc- $(S)$-photo-leucine was efficiently coupled to peptides (EDCIHOAt) or deprotected (4 N HC1) to give the free amino acid in quantitative yield. This route is a significant improvement over the original six-step synthesis of $(S)$-photo-leucine, which proceeded in low yield and required enzymatic resolution of a racemic intermediate. ${ }^{7}$ Synthesis of 2 followed the solution-phase route developed by Boger and coworkers ${ }^{13}$ with slight modifications. The diazirine side chain was stable to ambient light and the acidic and basic conditions used to prepare $\mathbf{2}$. We also synthesized $\mathbf{3}$ as a photo-stable control compound. Both $\mathbf{2}$ and $\mathbf{3}$ were equipotent to the natural product $\mathbf{1}$ at inhibiting VCAM expression in transfected cells $\left(\mathrm{EC}_{50} \sim 25 \mathrm{nM}\right.$, Figure SI).

We incubated a crude ER microsome fraction with $500 \mathrm{nM} 2$ and irradiated the mixture with $\sim 350 \mathrm{~nm}$ light for $1 \mathrm{~min}$. Proteins were denatured in 1\% sodium dodecylsulfate (SDS) and subjected to standard click chemistry conditions using a rhodamine-azide reporter (see Supporting Information). Following electrophoresis, in-gel fluorescent scanning revealed a major rhodamine-labeled protein with an apparent molecular weight of $\sim 50 \mathrm{kDa}$ (Figure $2 \mathrm{~A}$, lane 1). Labeling of this protein required both UV light (lane 5) and 2 (lane 6), and was competed by excess 3 (lanes $2-4$ ). Weak labeling of two additional proteins ( $\sim 60 \mathrm{kDa}$ and $\sim 40$ $\mathrm{kDa}$ ) was not competed by excess $\mathbf{3}$ and is likely non-specific. Background labeling by the rhodamine-azide, independent of UV light or $\mathbf{2}$, was also observed (lanes 5 and 6).

The major crosslinked protein migrated on SDS gels with the same relative mobility as Sec61 $\alpha$, the largest subunit of the Sec61 complex (Figure S2). Consistent with Sec61 $\alpha$ as the primary target of 2 , the $\sim 50 \mathrm{kDa}$ rhodamine-labeled protein was immuno-precipitated directly from the click reaction mixture with an antibody raised against $\operatorname{Sec} 61 \alpha$, but not with a control antibody (Figure 2B). 
To independently confirm that Sec61 $\alpha$ is the photo-crosslinked protein, we prepared proteoliposomes reconstituted from either a detergent extract of ER microsomes, a Sec61depleted extract, or a depleted extract replenished with purified Sec61 complex. ${ }^{17}$ Depletion of the intact Sec61 complex from the detergent extract using antibodies against Sec61 $\beta^{18}$ was $\sim 90 \%$ efficient (as judged by immunoblotting for the $\alpha$ and $\beta$ subunits), whereas other ER proteins were not affected (Figure S3). Compared to proteoliposomes derived from control extracts (Figure 2C, lane 3), photo-crosslinking of 2 to the $\sim 50 \mathrm{kDa}$ protein was significantly diminished in Sec61-depleted proteoliposomes (lane 1) and was restored after adding back purified Sec61 complex (lane 2). We conclude that Sec61 $\alpha$, thought to form the channel through which all proteins transit as they enter the secretory pathway, is the primary target of $\mathbf{2}$ in the ER.

Photo-crosslinking of $\mathbf{2}$ to Sec61 $\alpha$ is remarkably selective given the proteomic complexity of the ER, which contains hundreds of membrane and luminal proteins, ${ }^{19}$ Sec61 $\alpha$ is a relatively minor constituent ( $0.7 \%$ of total ER protein) ${ }^{20} \mathrm{We}$ attribute this high selectivity to two factors. First, due to its similar size, shape, and hydrophobicity, photo-leucine likely forms intimate contacts with Sec61 $\alpha$ in a manner similar to the leucine side chain of $\mathbf{1}$. Second, the short lifetime (nanoseconds) 21 of the carbene derived from 2 (Figure 1) ensures that molecules not bound to Sec61 $\alpha$ are rapidly quenched by intramolecular rearrangement, solvent, or membrane lipids. Despite the short lifetime, the photo-crosslinking yield of $\mathbf{2}$ to Sec61 $\alpha$ was estimated to be $\sim 23 \%$ (Figure S4). Thus, depending on the specific application, alkyl diazirines may offer advantages over the widely used benzophenone crosslinker. The modular cyclodepsipeptide scaffold of $\mathbf{1}$ should facilitate installation of a diazirine at multiple positions. High-resolution mapping of the crosslinking site(s) by mass spectrometry will likely shed light on the mechanism by which these compounds selectively inhibit cotranslational translocation.

\section{Supplementary Material}

Refer to Web version on PubMed Central for supplementary material.

\section{Acknowledgements}

This work was supported by the NIH (GM81644), the intramural research program of the NICHD, and the Scleroderma Research Foundation.

\section{References}

1. For reviews, see (a) Sadakane Y, Hatanaka Y. Anal Sci 2006;22:209-218. [PubMed: 16512410] (b) Kotzyba-Hibert F, Kapfer I, Goeldner M. Angew Chem Int Ed Engl 1995;34:1296-1312.

2. Dormán G, Prestwich GD. Biochemistry 1994;33:5661-5673. [PubMed: 8180191]

3. Brunner J. Amu Rev Biochem 1993;62:483-514.

4. For recent examples, see (a) Kotake Y, Sagane K, Owa T, Mimori-Kiyosue Y, Shimizu H, Uesugi M, Ishihama Y, Iwata W, Mizui Y. Nat Chem Biol 2007;22Advanced online publication (b) Fuwa H, Takahashi Y, Konno Y, Watanabe N, Miyashita H, Sasaki M, Natsugari H, Kan T, Fukuyama T, Tomita T, Iwatsubo T. ACS Chem Biol 2007;2:408-418. [PubMed: 17530731]

5. Kauer JC, Erickson-Viitanen S, Wolfe HR Jr, DeGrado WF. J Biol Chem 1986;261:10695-10700. [PubMed: 3733726]

6. (a) Chin JW, Martin AB, King DS, Wang L, Shultz PG. Proc Natl Acad Set 2002;99:11020-11024. (b) High S, Martoglio B, Görlich D, Andersen SSL, Ashford AJ, Giner A, Hartmann E, Prehn S, Rapoport TA, Dobberstein B, Brunner J. J Biol Chem 1993;268:26745-26751. [PubMed: 8253810]

7. Suchanek M, Radzikowska A, Thiele C. Nat Meth 2005;2:261-268.

8. Vila-Perelló M, Pratt MR, Tulin F, Muir TW. J Am Chem Soc 2007;129:8068-8069. [PubMed: 17567014] 
9. (a) Foster CA, Dreyfuss M, Mandak B, Meingassner JG, Naegeli HU, Nussbaumer A, Oberer L, Scheel G, Swoboda EM. J Dermatol 1994;21:847-854. [PubMed: 7531725] (b) Boger DL, Keim H, Oberhauser B, Schreiner EP, Foster CA. J Am Chem Soc 1999;121:6197-6205.

10. Garrison JL, Kunkel EJ, Hegde RS, Taunton J. Nature 2005;436:285-289. [PubMed: 16015336]

11. Besemer J, Harant H, Wang S, Oberhauser B, Marquardt K, Foster CA, Schreiner EP, de Vries JE, Dascher-Nadel C, Lindley IL. Nature 2005;436:290-293. [PubMed: 16015337]

12. Osborne AR, Rapoport TA, van den Berg B. Annu Rev Cell Dev Biol 2005;21:529-550. [PubMed: 16212506]

13. Chen Y, Bilban M, Foster CA, Boger DL. J Am Chem Soc 2002;124:5431-5440. [PubMed: 11996584]

14. (a) Speers AE, Cravatt BF. Chem Biol 2004;11:535-546. [PubMed: 15123248] (b) Cohen MS, Hadjivassiliou H, Taunton J. Nat Chem Biol 2007;3:156-160. [PubMed: 17259979]

15. Cornish VW, Hahn KM, Shultz PG. J Am Chem Soc 1996;118:8150-8151.

16. Church RFR, Weiss MJ. J Org Chem 1970;35:2465-2471.

17. Görlich D, Rapoport TA. Cell 1993;75:615-630. [PubMed: 8242738]

18. Fons RD, Bogert BA, Hegde RS. J Cell Biol 2003;160:529-539. [PubMed: 12578908]

19. Gilchrist A, Au CE, Hiding J, Bell AW, Fernandez-Rodriguez J, Lesimple S, Nagaya H, Roy L, Gosline SJC, Hallett M, Paiement J, Kearney RE, Nilsson T, Bergeron JJM. Cell 2006;127:12651281. [PubMed: 17174899]

20. Guth S, Völzing C, Müller A, Jung M, Zimmermann R. Eur J Biochem 2004;271:3200-3207. [PubMed: 15265039]

21. Ford F, Yuzawa T, Platz MS, Matzinger S, Fülscher M. J Am Chem Soc 1998;120:4430-4438. 


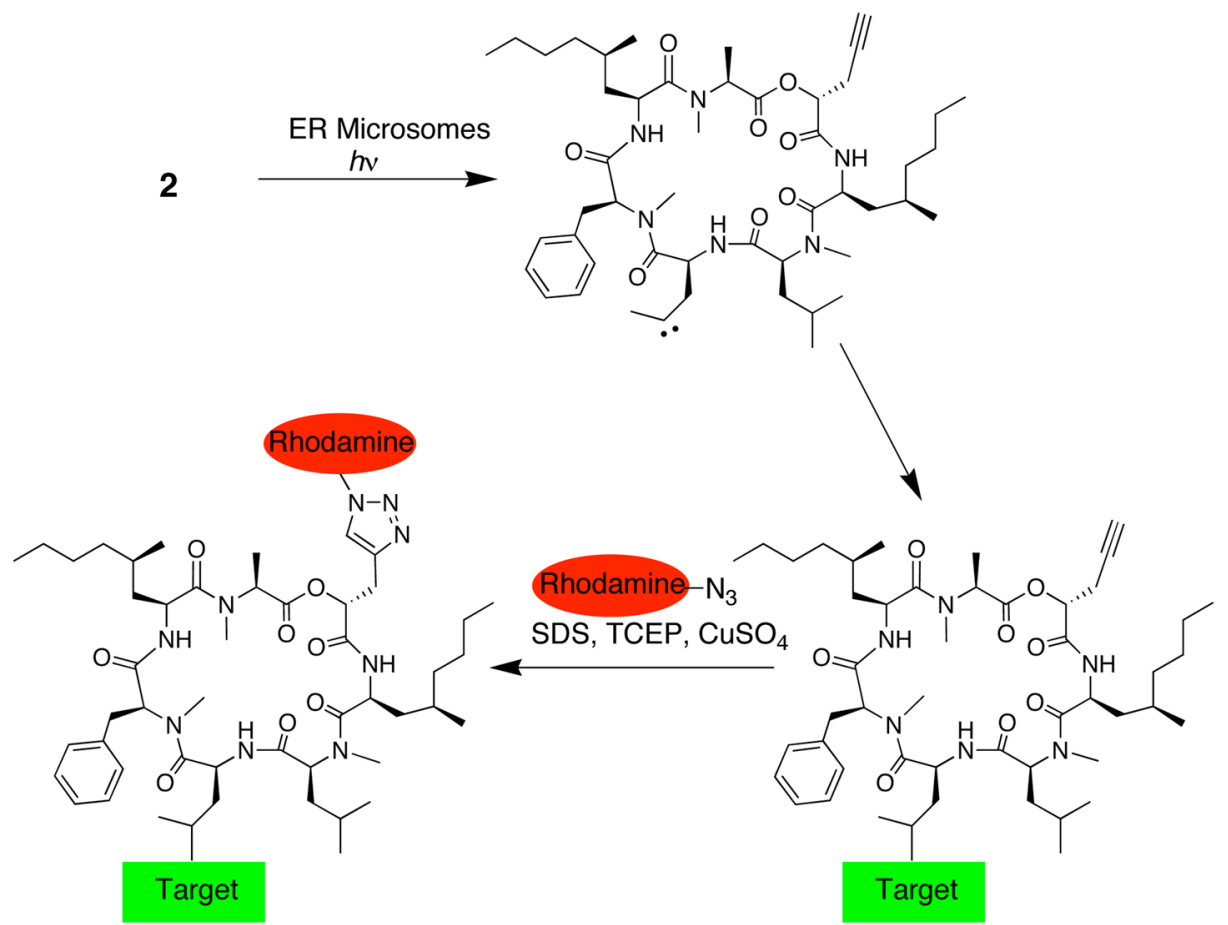

Figure 1.

Photoaffinity labeling strategy to identify the target of $\mathbf{2}$. 
(A)

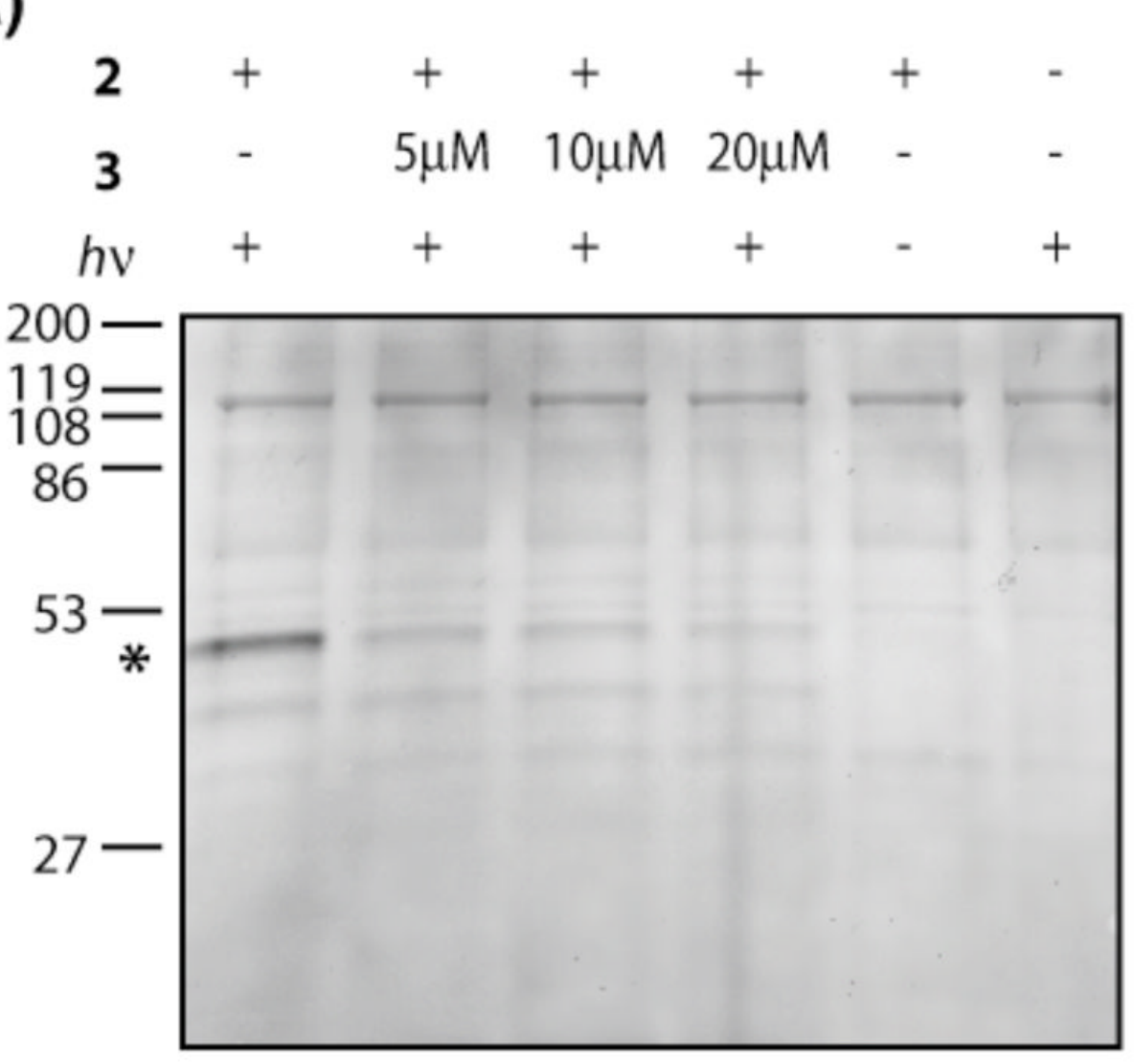

\section{Rhodamine Fluorescence}

(B)
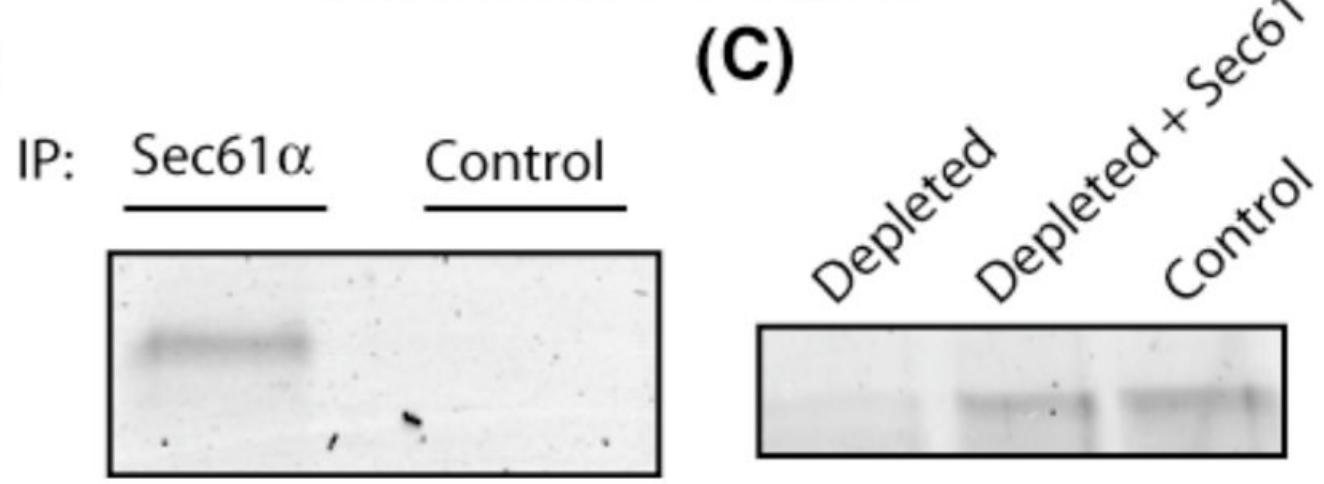

Figure 2.

(A) Photo-crosslinking of $\mathbf{2}$ in the presence of ER microsomes, followed by click chemistry with a rhodamine-azide reporter. An asterisk marks the major photo-crosslinked protein. (B) Sec61 $\alpha$ antibody or rabbit serum (control) was added to photolysis/click reactions, and immuno-precipitates (IP) analyzed by in-gel fluorescent scanning. (C) Proteoliposomes derived from control extracts (lane 3), Sec61-depleted extracts (lane 1), or depleted extracts replenished with purified Sec61 (lane 2) were photolyzed in the presence of $\mathbf{2}$ and analyzed by click chemistry/in-gel fluorescent scanning. The major crosslinked protein at $\sim 50 \mathrm{kDa}$ is shown. 


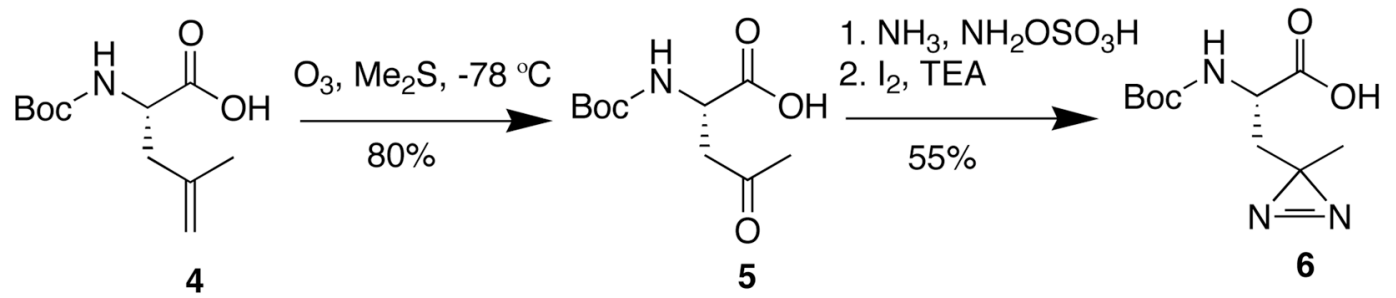

Scheme 1.

Synthesis of Boc- $(S)$-photo-leucine 